\section{Enzyme-multiplied Immunoassay}

\author{
C. Krüger und W. Stöcker \\ Euroimmun Medizinische Labordiagnostika AG, Lübeck, \\ Deutschland
}

\section{Synonym(e) EMIT}

Englischer Begriff EMIT; enzyme-multiplied immunoassay technique

Definition Homogener Immunoassay zum Nachweis und zur quantitativen Bestimmung von Antigenen mit geringer Molekularmasse (Haptenen), bei dem das enzymmarkierte Reagenzantigen mit dem unmarkierten Antigen der Probe um begrenzt zur Verfügung stehende Antikörperbindungsstellen konkurriert. Dabei ist das enzymmarkierte Antigen in freier Form entweder enzymatisch aktiv und wird nach der Antikörperbindung inaktiviert oder umgekehrt. Als Messsignal dient die Änderung der enzymatischen Aktivität.

Physikalisch-chemisches Prinzip Bei der EMIT wird eine spezielle Art der Enzymmarkierung verwendet. Das Enzym, z. B. Glukose-6-Phosphat-Dehydrogenase, wird in der Nähe seines aktiven Zentrums mit einem Antigen (Hapten) gekoppelt, sodass ein gegen das Antigenmolekül gerichteter Antikörper nach seiner Bindung das katalytische Zentrum des Enzyms blockiert oder hemmt. Ein Substratumsatz ist somit nicht mehr möglich. Nach dem kompetitiven Prinzip konkurrieren das Antigen der Probe und enzymmarkiertes Antigen um eine begrenzte Anzahl Antikörper im Reaktionsansatz. Gemessen wird die im Reaktionsansatz verbleibende Enzymaktivität. Das Messsignal verhält sich direkt proportional zur Antigenkonzentration in der Probe. Bei Verwendung des
Enzyms Malatdehydrogenase zur Markierung des Antigens kommt es bei Bindung eines gegen das Antigen gerichteten Antikörpers zu einer Erhöhung der Enzymaktivität, sodass sich das Messsignal hier umgekehrt proportional zur Konzentration des Antigens in der zu bestimmenden Probe verhält.

Einsatzgebiet Nachweis von Antigenen mit kleiner Molekularmasse(Haptenen), wie Medikamenten (z. B. Ciclosporin) und Drogen aus Körperflüssigkeiten (z. B. Amphetamine, Benzodiazepine, Opiate) ( $\triangleright$ Drogenscreening).

Untersuchungsmaterial Serum, Plasma, Urin.

Fehlermöglichkeit Beim Nachweis von Drogen und Medikamenten kann es zu Kreuzreaktionen mit anderen Medikamenten oder auch mit Nahrungsmitteln kommen. Daher müssen entsprechende Angaben berücksichtigt und positive Befunde i. d. R. mittels $>$ Chromatographie-Verfahren ( $\triangleright$ Massenspektrometrie) bestätigt werden.

Praktikabilität - Automatisierung - Kosten Es sind sowohl manuelle als auch automatisierte EMIT verfügbar. Der Aufbau von EMIT zur Bestimmung von Antigenen mit großer Molekularmasse ist schwierig.

Bewertung - Methodenhierarchie (allg.) Ein Vorteil der Methode ist die einfache Durchführung: „Mische und messe“ (engl.: ,mix and read“).

\section{Literatur}

Wild D (2005) The immunoassay handbook, 3. Aufl. Nature Publishing Group, New York, S 185-187 